\title{
Seismic Hazard Assessment for Japan after the 2011 Tohoku-Oki Mega-Thrust Earthquake (Mw9.0)
}

\author{
Hiroyuki Fujiwara and Nobuyuki Morikawa \\ National Research Institute for Earth Science and Disaster Prevention, Ibaraki 305-0006, Japan
}

\begin{abstract}
The Tohoku-Oki earthquake (Mw 9.0) of March 11, 2011, was the largest event in the history of Japan. This magnitude 9.0 mega-thrust earthquake initiated approximately $100 \mathrm{~km}$ off-shore of Miyagi prefecture and the rupture extended 400-500 km along the Pacific plate. Due to the strong ground motions and tsunami associated by this event, approximately twenty thousand people were killed or missing and more than 220 thousands houses and buildings were totally or partially destroyed. This mega-thrust earthquake was not considered in the national seismic hazard maps for Japan that was published by the HERP (headquarters for earthquake research promotion) of Japan. By comparing the results of the seismic hazard assessment and observed strong ground motions, we understand that the results of assessment were underestimated in Fukushima prefecture and northern part of Ibaraki prefecture. Its cause primarily lies in that it failed to evaluate the Mw 9.0 mega-thrust earthquake in the long-term evaluation for seismic activities. On the other hand, another cause is that we could not make the functional framework which is prepared for treatment of uncertainty for probabilistic seismic hazard assessment work fully. Based on the lessons learned from this earthquake disaster and the experience that we have engaged in the seismic hazard mapping project of Japan, we consider problems and issues to be resolved for probabilistic seismic hazard assessment and make new proposals to improve probabilistic seismic hazard assessment for Japan.
\end{abstract}

Key words: Probabilistic seismic hazard, long-term evaluation, strong ground motion, national seismic hazard maps for Japan, Tohoku-Oki earthquake.

\section{Introduction}

The Tohoku-Oki earthquake (Mw 9.0) of March 11, 2011, was the largest event in the history of Japan. This mega-thrust earthquake was not considered in the national seismic hazard maps for Japan that was published by the Headquarters for Earthquake Research Promotion of Japan [1]. Based on the lessons learned from this earthquake disaster and the experience that we have engaged in the seismic hazard mapping project of Japan, we consider problems and issues to be resolved for probabilistic seismic hazard assessment and make new proposals to improve probabilistic seismic hazard assessment for Japan.

\section{Strong Ground Motion}

This magnitude 9.0 mega thrust earthquake initiated approximately 100 km off-shore of Miyagi prefecture

Corresponding author: Hiroyuki Fujiwara, Dr., research field: applied seismology. E-mail: fujiwara@bosai.go.jp. and the rupture extended 400-500 $\mathrm{km}$ along the subducting Pacific plate. Due to the large ground motions and tsunami associated by this event, approximately twenty thousand people were killed or missing and more than 220 thousands houses and buildings were totally or partially destroyed.

The Tohoku-Oki earthquake was the first M9-class earthquake that is closely recorded by dense seismograph network. The ground motions were recorded at more than $1200 \mathrm{~K}-\mathrm{NET}$ [2] and KiK-net [3] stations (Fig. 1). The PGA (peak ground accelerations) exceeded $1 \mathrm{~g}$ at 20 sites and the largest PGA, 2,933 gals $\left(2,933 \mathrm{~cm} / \mathrm{s}^{2}\right)$, was observed at the K-net Tsukidate station (MYG004).

Huge numbers of large aftershocks and induced earthquakes including M7-class crustal and intraslab earthquakes have been recorded. Those earthquakes occurred not only in the source area but also several hundred kilometers away. Some of them were located 
much nearer to the populated urban areas than the main shock and human fatalities as well as severe building damages were caused by large ground shakings.
As shown in Fig. 2, the observed waveforms from the main shock are very complex, depending on the region, accelerograms show one to three conspicuous

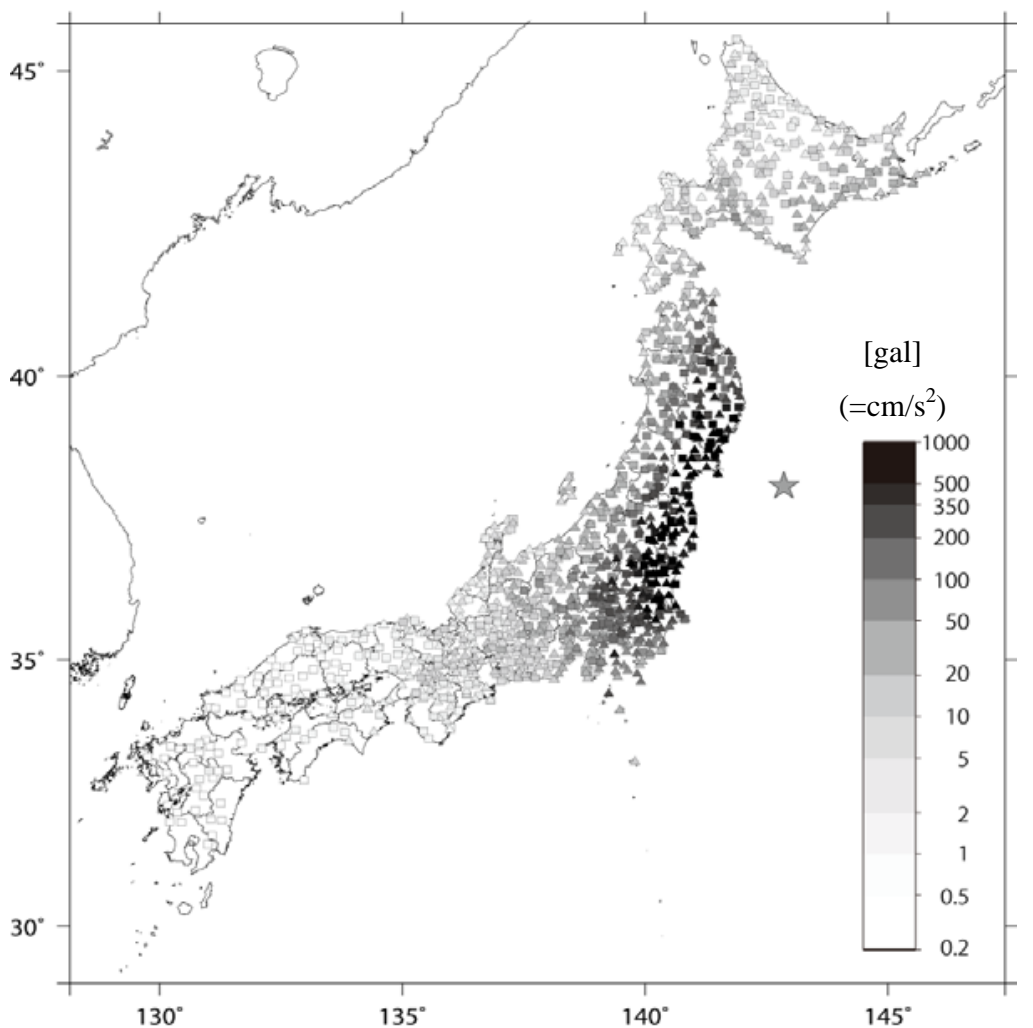

Fig. 1 The peak ground accelerations recorded at K-NET $(\Delta)$ and KiK-net $(\Delta)$ stations.
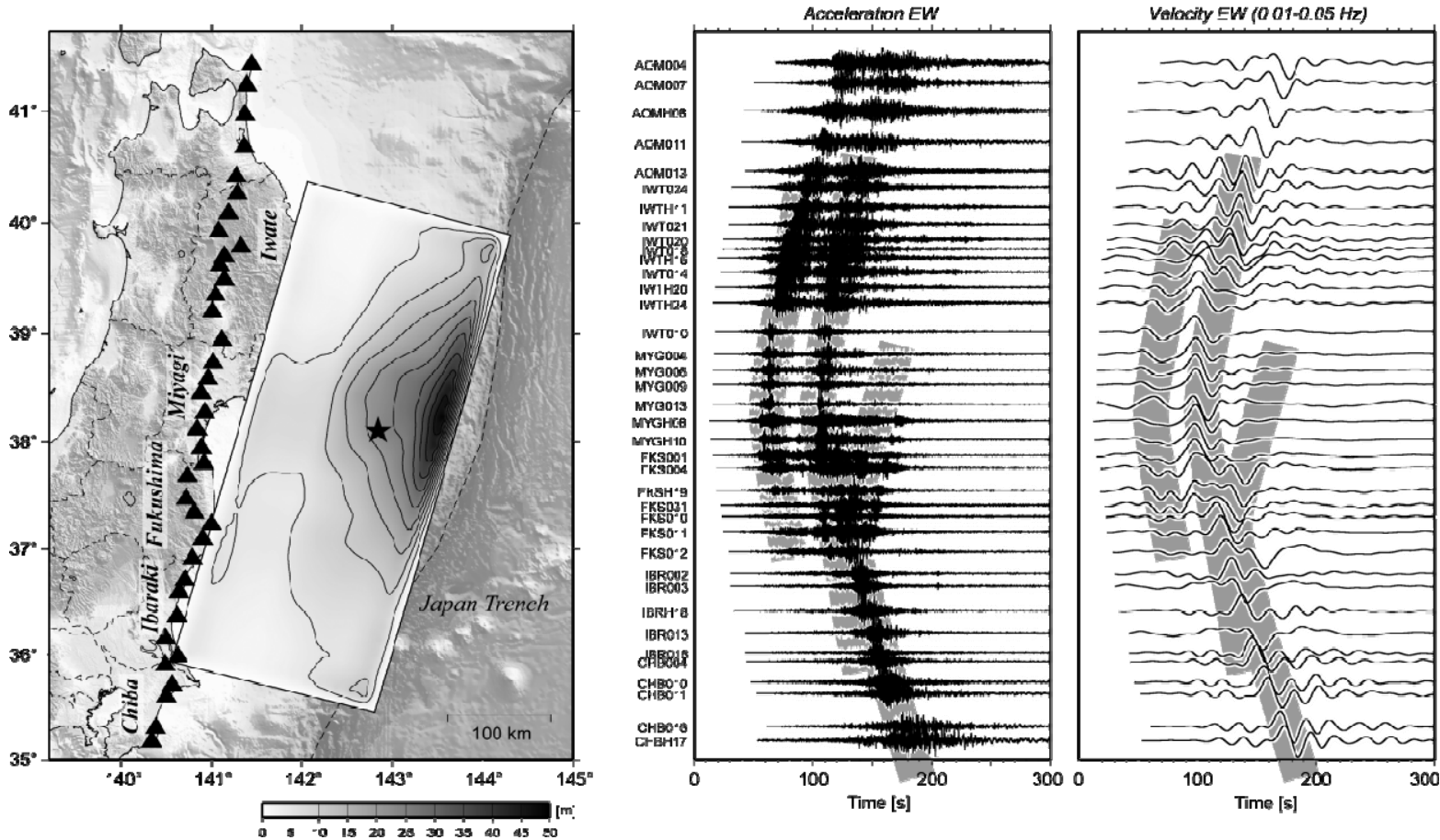

Fig. 2 The observed waveforms and distribution of slip on the fault [4]. 
and long-duration phases as well as several phases with smaller amplitudes and shorter durations. A paste-up of accelerograms in IWT (Iwate), MYG (Miyagi) and FKS (Fukushima) prefectures ordered by latitude from north displays an initial strong seismic phase first observed at Miyagi stations and then propagated towards the north and south. A subsequent phase uniformly delayed by approximately $40 \mathrm{~s}$ is also clearly observed in the paste-up. In the southern region, IBR (Ibaraki) and CHB (Chiba) prefectures, only one distinct phase is observed.

On the other hand, fault rupture inverted by a multi-time window analysis using the strong-motion waveforms is characterized by one large slip area with maximum slip of $48 \mathrm{~m}$ which extends from the area near the hypocenter toward the shallow part of the fault plane, far off the coast of Iwate, Miyagi and Fukushima prefectures [4].

\section{Comparison between the Strong-Motions of Tohoku Earthquake and the Seismic Hazard Maps}

Fig. 3 shows a comparison between the observed JMA (Japan Meteorological Agency) seismic intensities of the Tohoku-Oki earthquake and JMA seismic intensity distribution for $2 \%$ probability of exceedance in 50 years, which is one of the probabilistic seismic hazard map. In the probabilistic seismic hazard map, the seismic intensity of $2 \%$ probability of exceedance in 50 years has been evaluated as 6- or 6+ in Miyagi prefecture and in the southern Kanto region, which covers almost the observed ground motion for the Tohoku-Oki earthquake. However, in the northern area of Ibaraki Prefecture and in Fukushima Prefecture where large earthquakes with high probability of occurrence had not been expected, the seismic intensity $6+$ was observed at the points where seismic intensity 5- or 5+ was expected in the seismic hazard map. As you can see from this comparison, predicted ground motion level in the probabilistic seismic hazard map was clearly underestimated in Fukushima Prefecture and the northern part of Ibaraki Prefecture for the Tohoku-Oki earthquake (Mw 9.0). This is primarily because, in the long-term evaluation that has been the basis of the seismicity model for the probabilistic seismic hazard map, the occurrence of great earthquakes Mw 9.0 has not been evaluated. On the other hand, the cause of underestimate also lies in the inability to function well the whole framework of

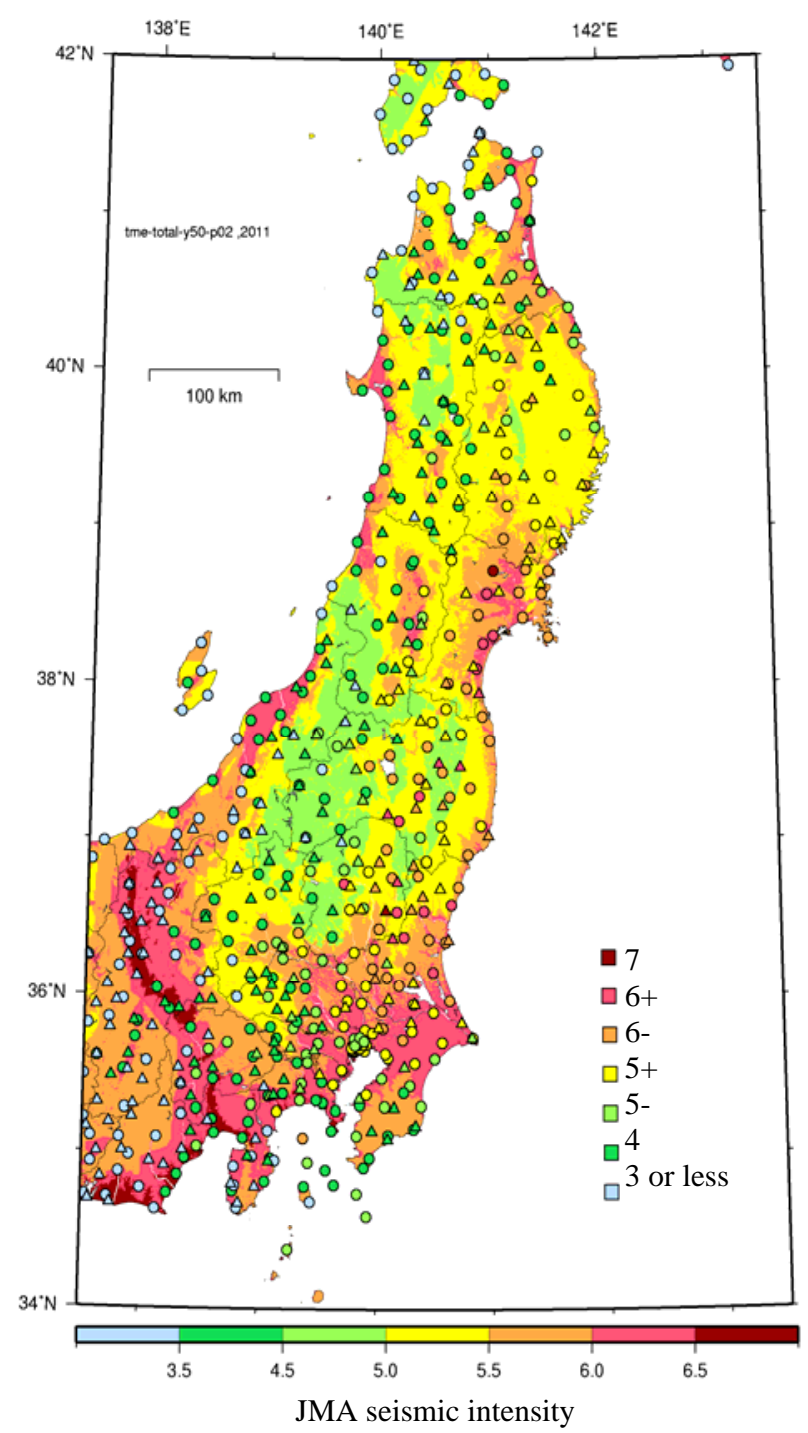

Fig. 3 Comparison between the observed JMA seismic intensities( $($ :K-NET, $\Delta:$ KiK-net) of the Tohoku-Oki earthquake and JMA seismic intensity distribution for $2 \%$ probability of exceedance in 50 years, which is one of the seismic hazard (Refer symbol for the values of probabilistic hazard in the map) maps for Japan. 
probabilistic seismic hazard assessment methods under the circumstances that many issues are left unresolved in seismology.

\section{National Seismic Hazard Maps for Japan}

The Headquarters for Earthquake Research Promotion of Japan published a new version of the national seismic hazard maps for Japan in July 2009, which was initialized by the ERCJ (Earthquake Research Committee of Japan) on a basis of long-term evaluation of seismic activity, and on a basis of strong-motion evaluation. The NIED (National Research Institute for Earth Science and Disaster Prevention), in the meantime, also promoted a special research project "National Seismic Hazard Mapping Project of Japan" to support the preparation of the seismic hazard maps [5]. Under guidance of ERCJ, we have carried out the study of the hazard maps.

The hazard maps consist of two kinds of maps. One is a PSHM (probabilistic seismic hazard map) that shows the relation between seismic intensity value and its probability of exceedance within a certain time period. The other one is a SESM (scenario earthquake shaking map).

The examples of PSHMs are maps of probabilities that JMA seismic intensity exceeds 5-, 5+, 6- and 6+ in 30 or 50 years, and maps of the JMA seismic intensity corresponding to the exceedance probability of $3 \%$ and $6 \%$ in 30 years and of $2 \%, 5 \%, 10 \%$ and $39 \%$ in 50 years. We classify earthquakes in and around Japan into three categories such as the characteristic subduction zone earthquakes, other subduction zone earthquakes, and crustal earthquakes. PSHMs for three earthquake category are also evaluated. For the PSHM, we use empirical attenuation relation for strong-motion, which is followed the seismic activity modeling in the basis of long-term evaluation of seismic activity by ERCJ. Both of peak velocities on the engineering bedrock and on ground surface are evaluated for sites with approximately $0.25 \mathrm{~km}$ spacing in the basis of the 7.5-Arc-Second Engineering Geomorphologic
Classification Database by Wakamatsu and Matsuoka [6]. The JMA seismic intensities on ground surface are evaluated from peak ground velocity by using an empirical formula.

The SESMs are evaluated for 485 scenario earthquakes of all major active faults in Japan. Selection of a specified scenario is essential to make a scenario earthquake shake map. The basic policy of the selection is that we choose the most probable case. We assume several cases of the characteristic source model and compare the results of them to show deviation of strong-motion evaluation due to uncertainties. For the SESMs, based on the source modeling for strong-motion evaluation we adopt a hybrid method to simulate waveforms on the engineering bedrock and peak ground velocity. The hybrid method aims to evaluate strong-motions in a broadband frequency range and is a combination of a deterministic approach using numerical simulation methods, such as the finite difference method, for low frequency range and a stochastic approach using the empirical or stochastic Green's function method for high frequency range. A lot of parameters on source characterization and modeling of underground structure are required for the hybrid method. The standardization of the setting parameters for the hybrid method is studied. We summarize the technical details on the hybrid method based on the Recipe for strong-motion evaluation, which are published by the ERCJ.

The national seismic hazard maps for Japan are a comprehensive integration from all of the research aspects conducted by ERCJ. It contains information of all necessary data for producing the maps. To cross-check and promote the use of the national seismic hazard maps, an engineering application committee was established by NIED. Under the committee guidance, we have developed an open web system to provide seismic hazard information interactively, and name this system as Japan Seismic Hazard Information Station, J-SHIS [7]. We aim to distribute a process of uncertainty evaluation and to 
meet multi-purpose needs in engineering fields. The information provided from J-SHIS includes not only results of the hazard maps but also various information required in the processes of making the hazard maps, such as data on seismic activity, source models and underground structure.

\section{Probabilistic Seismic Hazard Assessment in the Seismic Hazard Maps}

The methodology of probabilistic seismic hazard assessment was used for preparing the probabilistic seismic hazard maps for Japan. Probabilistic seismic hazard assessment method is a technique that has been developed in order to set ground motion level corresponding to certain probability of exceedance. In probabilistic seismic hazard assessment, the uncertainty for occurrence of earthquake and level of ground motion are considered. In the national seismic hazard maps for Japan, the map that shows the probability of exceedance for a certain level of ground motion has been used as a typical map.

To prepare probabilistic seismic hazard maps, seismic hazard assessment methods described below have been adopted. Seismic hazard assessment analyzes the relationship between the following three parameters: the ground motion intensity that occur in the future at a given site, the target period, and target probability. The brief outline of the procedure of seismic hazard assessment in preparation of the probabilistic seismic hazard maps is shown below:

(1) Model the earthquake activities around a target site according to the ERCJ's earthquake classification;

(2) For each earthquake modeled, evaluate the probability of the earthquake magnitude, the probability of the distance from the target site, and the probability of earthquake occurrence;

(3) Set a probability model for presuming the ground motion intensity for an earthquake of a given magnitude and distance. For each modeled earthquake, evaluate the probability of the intensity of the ground motions caused by that earthquake within the target period exceeding a certain value. Use empirical attenuation relations for strong motion evaluation. Specifically, first derive the peak velocity on the engineering bedrock based on an attenuation relation using the shortest distance from the target site to the fault plane, then multiply the derived value by the site amplification factor to obtain the peak velocity, and finally use the relation between the peak velocity and the JMA instrumental seismic intensity to evaluate the seismic intensity on the ground surface;

(4) Repeat the operation above for the same number of times as the number of the modeled earthquakes, and sum up the results to obtain the probability of the intensity of the ground motions occurring within the target period exceeding a certain value by at least one degree, when all earthquakes are taken into consideration.

In this manner, seismic hazard assessment is conducted for each site, and by fixing any two parameters of the ground motion intensity, period, and probability, the value of the remaining parameter are obtained. The probabilistic seismic hazard maps show the distribution of such values.

For stochastic seismic hazard assessment, it is necessary to model all the earthquakes that may occur in the future. Basically, based on the results on long-term evaluation by HERP, we construct a model of seismic activity. However, long-term evaluation is intended to be used for general disaster prevention activities and it was focused to assess the earthquakes that are considered likely to occur. Therefore, the earthquakes had been evaluated are only part of future earthquakes that may occur. To construct the model needed to evaluate the probabilistic seismic hazard, it becomes necessary to fill the gap and a model for background earthquakes is required. In probabilistic seismic hazard assessment, it has become essentially important and difficult issues to model earthquakes that are low probability of occurrence and have not been assessed in the long-term evaluation by HERP. 


\section{Seismic Actibity Model for Probabilistic Seismic Hazard Maps}

In the following, in order to examine more specific issues, we summarized the seismic activity model that was used for the probabilistic seismic hazard maps.

For the source fault regions of the Tohoku-Oki earthquake, the model had been implemented based on the "Long-term evaluation of seismic activity for the region from the off Sanriku to the off Boso" [8]. In the long-term evaluation, the entire area is divided into eight regions and the evaluation for seismic activity had been conducted in each region (Fig. 4a). The results of the long-term evaluation are summarized in Table 1.

For each region, based on the records for earthquakes occurred in the past, by analyzing the pattern of occurrence, the presence of characteristic earthquake was evaluated. For the regions where the presence of some specific size earthquakes was observed, the size of earthquakes and the interval between earthquakes have been evaluated. Typical examples include the Miyagi-Oki earthquake.

On the other hand, in areas that were difficult to evaluate because no sufficient data were obtained, probability of earthquake occurrence was calculated by assuming a Poisson process without specifying where they occur. In addition, for the region where clear evidence of past earthquakes had not been obtained, for example, the off Boso area, no specific assessment was made and as the evaluation results, "Unknown" had been shown. Thus, in the long-term evaluation that was conducted before the Tohoku earthquake, evaluation had been made by the idea that large earthquakes of
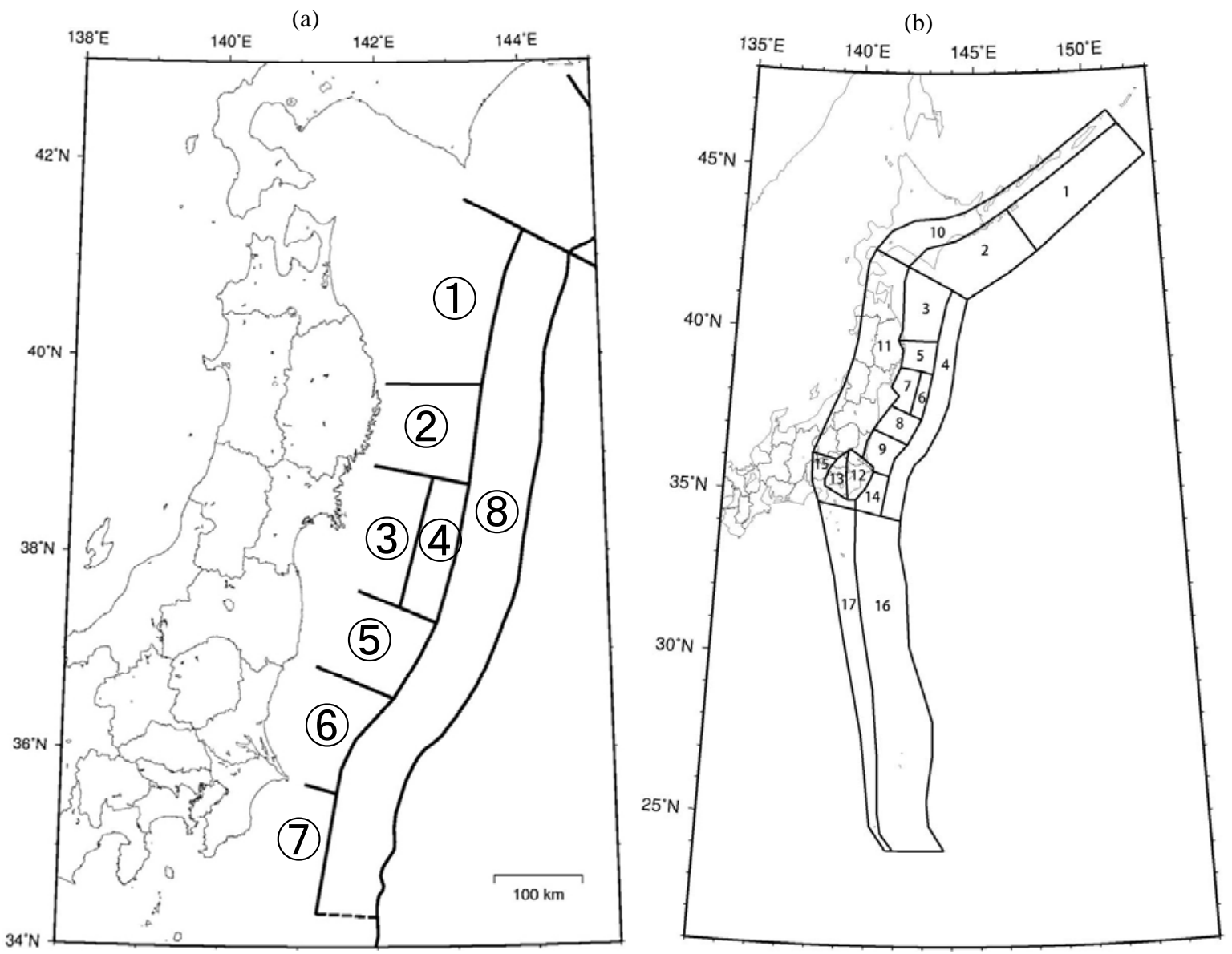

Fig. 4 The areas: (a) Target areas for "Long-term evaluation of seismic activity for the region from the off Sanriku to the off Boso"; (b) Zoning of background earthquakes for the Pacific plate. 
Table 1 Long-term evaluation of seismic activity for the region from the off Sanriku to the off Boso.

\begin{tabular}{|c|c|c|}
\hline Earthquake & Magnitude & Occur. prob. within 30 years \\
\hline Characteristic earthquake in (1) & Approx. M8.0 & $0.2 \%-0 \%$ \\
\hline $\begin{array}{l}\text { Interplate earthquakes other than characteristic } \\
\text { earthquake in (1) }\end{array}$ & M7.1-M7.6 & About $90 \%$ \\
\hline Earthquakes in (2) & Unknown & Unknown \\
\hline Miyagi-ken-Oki earthquake in (3) & Approx. M7.5 & $99 \%$ \\
\hline Interplate earthquakes in (4) & $\begin{array}{l}\text { Approx. M7.7 } \\
\text { (M8.0 for correlated with Miyagi-ken-Oki } \\
\text { earthquake) }\end{array}$ & $80 \%-90 \%$ \\
\hline Interplate earthquakes in (5) & $\begin{array}{l}\text { Approx. M7.4 } \\
\text { (Successive occurrence of multiple earthquakes) }\end{array}$ & About $7 \%$ or less \\
\hline Interplate earthquakes in (6) & M6.7-M7.2 & About $90 \%$ or more \\
\hline Earthquakes in (7) & Unknown & Unknown \\
\hline Tsunami earthquakes in (8) & Approx. Mt8.2 & About $20 \%$ \\
\hline Intraplate earthquakes (normal fault type) in (8) & Approx. M8.2 & $4 \%-7 \%$ \\
\hline
\end{tabular}

same size occur repeatedly in the same area, based on the observed records, historical documents and the results of geomorphological and geological surveys. If there was insufficient evidence and data, no assessment done and "Unknown” had been shown.

On the other hand, a significant point in "Long-term evaluation of seismic activity for the region from the off Sanriku to the off Boso" is that magnitude 8.2 tsunami earthquakes had been expected to occur with probability of $20 \%$ in the next 30 years in the region near the Japan trench from the northern off Sanriku to off Boso. If measures had been taken for tsunami earthquakes based on the evaluation, we might be able to reduce some of the victims of this earthquake, especially in south region from Fukushima prefecture.

In preparation of the probabilistic seismic hazard maps, in addition to the above mentioned long-term evaluation, earthquakes that are not even mentioned there are considered as "background earthquakes". The background earthquakes of the Pacific plate are shown in Fig. 4b. In these regions, interplate earthquakes that occur on the upper boundary of the Pacific plate and intraplate earthquakes in the Pacific plate have been considered. As shown in Table 2, upper limit of magnitude of the background earthquakes has been set for each region. This upper limit is determined by the maximum size of the historical earthquakes that occurred in each area before the Tohoku-Oki earthquake, excluding the large earthquakes that are targets for the long-term evaluation. In this regard, it had been pointed out that to use the previous maximum value for each region might lead to an underestimate as a result. However, there were many opposing views for setting an upper limit exceeding the previous largest event.

Table 2 Upper limit of magnitude of the background earthquakes for each region in Fig. $4 \mathrm{~b}$.

\begin{tabular}{lll}
\hline $\begin{array}{l}\text { Region No. in Fig. } \\
\text { (b) }\end{array}$ & Interplate \\
earthquake & $\begin{array}{l}\text { Intraplate } \\
\text { earthquake }\end{array}$ \\
\hline 1 & M6.9 & M7.4 \\
2 & M6.9 & M7.4 \\
3 & M7.0 & M7.0 \\
4 & M7.5 & None \\
5 & M7.0 & M7.0 \\
6 & M7.5 & M7.5 \\
7 & M7.2 & M7.2 \\
8 & M7.1 & M7.1 \\
9 & M7.3 & M7.3 \\
10 & None & M7.4 \\
11 & None & M7.1 \\
12 & M6.6 & M7.2 \\
13 & None & M7.2 \\
14 & M7.0 & M7.0 \\
15 & None & M7.0 \\
16 & M7.4 & M7.4 \\
17 & None & M7.0 \\
\hline
\end{tabular}




\section{Problems in Seismic Activity Model for Subduction Zone Earthquakes}

After the publication of the national seismic hazard maps for Japan in 2005, a series of inland earthquakes occurred and caused damage in the coastal areas of Sea of Japan. These earthquakes were not considered in the long-term evaluation. However, these earthquakes had been modeled as the background earthquakes for probabilistic seismic hazard maps. Framework of the seismic hazard assessment to complement the seismological knowledge said to be working at least.

However, not only the Tohoku-Oki earthquake had not been assessed in long-term evaluation, but also the earthquake could not be captured in a probabilistic model for assessing the uncertainty in seismic hazard assessment, which had been prepared to compensate for the lack of seismological knowledge. We could not properly assess the limits of seismological knowledge in a probabilistic seismic hazard assessment and were unable to reflect the evaluation results to our probabilistic model.

Why could we not take the Tohoku-Oki earthquake into account in the probabilistic seismic hazard assessment? Point of discussion to this question is found in the way of thinking about modeling of low probability subduction zone earthquakes. Compared with inland active fault earthquakes, subduction zone earthquakes have short interval of occurrence. Based on the historical experience of the past, the presence of characteristic large earthquakes that occur repeatedly in the same region was known. For the subduction zone earthquakes might occur around Japan, we had a delusion of understanding to some extent about the region, magnitude, and repetition interval of earthquakes.

For the preparedness against subduction zone earthquakes, the imminence of the earthquake was seen as an important factor in planning measures and measures tended to be taken for earthquake with high probability of occurrence.
On the other hand, for earthquakes with a long interval, such as several hundred or several thousand years, even though its size may be large, priority in earthquake preparedness tended to be relatively lower estimate.

By comparing the evaluation of subduction zone earthquakes and evaluation of earthquakes for active faults, the features of the evaluation become clearer. For earthquakes occur at active faults, the so-called characteristic earthquakes usually have repetition interval of thousands of years. Thus, even when evaluated using the BPT distribution, the occurrence probability in 30 years remain at most a few percent. Using a Poisson process, the probability is around 1\% at most. In order to take into account earthquakes at the fault zone with low degree of seismic activity, it is necessary to evaluate very infrequently events, such as once in several tens thousands years. If we took into account the low probability events even for subduction earthquakes similar to characteristic earthquakes at active faults, in the probabilistic seismic hazard assessment, we might be able to conduct hazard assessment considering earthquakes of a certain large scale as background earthquakes.

\section{To Probabilistic Seismic Hazard Assessment from Long-Term Evaluation}

Based on the lessons learned from the Tohoku-Oki earthquake, the revision of methodology for the long-term evaluation has been promoted in HERP. In previous long-term evaluation, based on observation data, historical records and the results of geological and topographic survey, earthquakes have been evaluated by using the idea that earthquakes of similar size occur repeatedly in the same area. In next long-term evaluation in the future, by improving the methodology, it has been aimed to take into account not only earthquakes that can be estimated from seismic data obtained in the past, but also earthquakes that have not been confirmed by historical records and observations, based on scientific evidence. After the techniques of 
long-term evaluation have been improved, we hope that many of the earthquakes that may occur in the future will be covered by new long-term evaluation.

On the other hand, it may be difficult to completely evaluate all possible earthquakes in the future by using the techniques of long-term evaluation that are based on the scientific methodology and the scientific knowledge, such as, observational records, historical records and the results of geological and topographic surveys. In probabilistic seismic hazard assessment, a framework for considering the uncertainty of the phenomenon itself and the limits of scientific knowledge, has been prepared using the stochastic and probabilistic method. It becomes a problem to establish a methodology to function the framework effectively.

In order to construct a probabilistic seismic activity model that encompasses the seismic activity of all possible earthquakes, it is necessary for the complement the long-term evaluation to establish a different methodology from that of long-term evaluation.

※ Source fault area for the Tohoku-Oki earthquake type:

(1) P shows that occurrence probability is calculated assuming Poisson process.

(2) $\mathrm{Mu}$ is the upper limit of magnitude, $\mathrm{Mu}=$ Interplate Eq./Intraplate Eq.

To achieve this, it is necessary to evaluate objectively the property of long-term evaluation in the modeling of seismic activity based on the long-term evaluation for the seismic hazard assessment. Also, it may be necessary to promote proper modeling of background earthquakes that encompasses all earthquakes without long-term evaluation.

For example, it may be possible to evaluate the magnitude of earthquakes from the area of the plate boundary that can be considered to cause earthquakes, and to assess the frequency of occurrence of earthquakes by using the Gutenberg-Richter formula that shows the relationship between the number of earthquakes and their magnitude. In its revision, it is essential to consider a new method of setting the scale for earthquakes, not limited by the idea of using the historical largest event for each small region.

After the Tohoku-Oki earthquake, HERP had been reviewing the long-term evaluation for the area in which the Tohoku-Oki earthquake occurred and released the revised version of the "Long-term evaluation of seismic activity for the region from the off Sanriku to the off Boso” in November 2011. In this revision, although the revision of the methodology of the long-term evaluation itself has not yet been made and the most part has remained a traditional evaluation, a new assessment has been made of the Tohoku-Oki type earthquake. Based on this evaluation, we have been making a revision of the seismic hazard assessment. In Table 3, we show the parameters of the seismic activity model for the revision of the probabilistic seismic hazard maps. In this revision, not only results of the long-term evaluation have been revised, but also the upper limits of background earthquakes have been revised. In addition, here we propose three models in order to consider uncertainty of seismic activity.

\section{Conclusions}

We have made a revision of the seismic hazard assessment based on the revised version of the "Long-term evaluation of seismic activity for the region from the off Sanriku to the off Boso". Revision of seismic activity model for other regions of Japan has been undergoing. After the revision of long-term evaluation for whole of Japan, we will recalculate seismic hazard. The followings are problems to be solved in the future.

(1) Modeling of seismic activity with no oversight to low-probability earthquakes.

For both subduction zone earthquakes and earthquakes at active faults, it is necessary to aim to model seismic activity that can be considered to events about once several thousand or several tens thousands of years. To achieve this goal, we need to 
Table 3 Seismic activity model for probabilistic seismic hazard maps based on the revision of long-term evaluation.

\begin{tabular}{|c|c|c|c|c|c|}
\hline $\begin{array}{l}\text { Region } \\
\text { No. } \\
\end{array}$ & $\begin{array}{l}\text { Earthquake } \\
\text { type }\end{array}$ & Previous model & $\begin{array}{l}\text { Revised } \\
\text { Model } 1 \\
\end{array}$ & $\begin{array}{l}\text { Revised } \\
\text { Model } 2 \\
\end{array}$ & $\begin{array}{l}\text { Revised } \\
\text { Model } 3\end{array}$ \\
\hline$※$ & Repeating Eq. & None & $\begin{array}{l}M=8.4-9.0 \\
P 30=0 \%\end{array}$ & $\begin{array}{l}M=8.4-9.0 \\
\mathrm{P} 30=0 \%\end{array}$ & \\
\hline \multirow{4}{*}{ (1) } & Repeating Eq. & $\begin{array}{l}\mathrm{M}=8.0 \\
\mathrm{P} 30=6.3 \%\end{array}$ & $\begin{array}{l}M=8.0 \\
P 30=7.3 \%\end{array}$ & $\begin{array}{l}\mathrm{M}=8.0 \\
\mathrm{P} 30=7.3 \%\end{array}$ & \\
\hline & Other Eq. & $\begin{array}{l}M=7.1-7.6 \\
\text { P30 }=93 \%(P)^{1)}\end{array}$ & $\begin{array}{l}\mathrm{M}=7.1-7.6 \\
\mathrm{P} 30=88 \%(\mathrm{P})\end{array}$ & $\begin{array}{l}\mathrm{M}=7.1-7.6 \\
\mathrm{P} 30=88 \%(\mathrm{P})\end{array}$ & \\
\hline & Background Eq. & $\mathrm{Mu}=7.0$ & $\mathrm{Mu}=7.0$ & $\mathrm{Mu}=7.0$ & \\
\hline & Repeating Eq. & None & None & None & \\
\hline \multirow{3}{*}{ (2) } & Other Eq. & None & None & None & \\
\hline & Background Eq. & $\mathrm{Mu}=7.0$ & $\mathrm{Mu}=8.0 / 7.5^{2)}$ & $\mathrm{Mu}=8.2 / 8.2$ & \\
\hline & Repeating Eq. & $\begin{array}{l}M=7.5 \\
P 30=100 \%\end{array}$ & $\begin{array}{l}\mathrm{M}=7.4 \\
\mathrm{P} 30=55 \%(\mathrm{P})\end{array}$ & None & \\
\hline \multirow[t]{3}{*}{ (3) } & Other Eq. & None & $\begin{array}{l}\mathrm{M}=7.0-7.3 \\
\mathrm{P} 30=61 \%(\mathrm{P})\end{array}$ & None & \\
\hline & Background Eq. & $\mathrm{Mu}=7.2$ & $\mathrm{Mu}=8.0 / 7.5$ & $\mathrm{Mu}=8.4 / 8.2$ & \\
\hline & Repeating Eq. & $\begin{array}{l}\mathrm{M}=7.7 \\
\mathrm{P} 30=81 \%\end{array}$ & $\begin{array}{l}M=7.9 \\
P 30=0\end{array}$ & & \\
\hline \multirow[t]{3}{*}{ (4) } & Other Eq. & None & $\begin{array}{l}\mathrm{M}=7.2-7.6 \\
\mathrm{P} 30=51 \%(\mathrm{P})\end{array}$ & Combined with (3) & \\
\hline & Background Eq. & $\mathrm{Mu}=7.5$ & $\mathrm{Mu}=8.0 / 7.5$ & & \multirow{3}{*}{$\begin{array}{l}\text { G-R model with } \\
\text { Poisson process } \\
\text { for total area }\end{array}$} \\
\hline & Repeating Eq. & $\begin{array}{l}\mathrm{M}=7.4 \\
\mathrm{P} 30=7.2 \%(\mathrm{P})\end{array}$ & $\begin{array}{l}\mathrm{M}=7.4 \\
\mathrm{P} 30=14 \%(\mathrm{P})\end{array}$ & None & \\
\hline \multirow[t]{3}{*}{ (5) } & Other Eq. & None & None & None & \\
\hline & Background Eq. & $\mathrm{Mu}=7.1$ & $\mathrm{Mu}=8.0 / 7.5$ & $\mathrm{Mu}=8.2 / 8.2$ & \\
\hline & Repeating Eq. & $\begin{array}{l}M=7.0 \\
P 30=99 \%\end{array}$ & $\begin{array}{l}M=7.0 \\
P 30=95 \%\end{array}$ & None & $\begin{array}{l}\text { Interplate } \\
\mathrm{Mu}=9.5\end{array}$ \\
\hline \multirow[t]{3}{*}{ (6) } & Other Eq. & None & $\begin{array}{l}\mathrm{M}=6.9-7.6 \\
\mathrm{P} 30=69 \%(\mathrm{P})\end{array}$ & None & Intraplate \\
\hline & Background Eq. & $\mathrm{Mu}=7.3$ & $\mathrm{Mu}=8.0 / 7.5$ & $\mathrm{Mu}=8.3 / 8.2$ & $\mathrm{Mu}=8.2$ \\
\hline & Repeating Eq. & None & None & None & \\
\hline \multirow{4}{*}{ (7) } & Other Eq. & None & None & None & \\
\hline & Background Eq. & $\mathrm{Mu}=7.0$ & $\mathrm{Mu}=8.0 / 7.5$ & $\mathrm{Mu}=8.3 / 8.2$ & \\
\hline & Repeating Tsunami Eq. & $\begin{array}{l}\mathrm{M}=8.2(6.8) \\
\mathrm{P} 30=20 \%(\mathrm{P})\end{array}$ & $\begin{array}{l}\mathrm{Mt}=8.6-9.0 \\
\mathrm{P} 30=25 \%(\mathrm{P})\end{array}$ & $\begin{array}{l}\mathrm{Mt}=8.6 \sim 9.0 \\
\mathrm{P} 30=25 \%(\mathrm{P})\end{array}$ & \\
\hline & $\begin{array}{l}\text { Repeating Eq. } \\
\text { (Normal fault) }\end{array}$ & $\begin{array}{l}\mathrm{M}=8.2 \\
\mathrm{P} 30=5.1 \%(\mathrm{P})\end{array}$ & $\begin{array}{l}\mathrm{M}=8.2 \\
\mathrm{P} 30=5.1 \%(\mathrm{P})\end{array}$ & $\begin{array}{l}\mathrm{M}=8.2 \\
\mathrm{P} 30=5.1 \%(\mathrm{P})\end{array}$ & \\
\hline \multirow[t]{2}{*}{ (8) } & Other Eq. & None & None & None & \\
\hline & Background Eq. & $\mathrm{Mu}=7.5$ & $\mathrm{Mu}=8.0 /$ None & $\mathrm{Mu}=8.0 /$ None & \\
\hline
\end{tabular}

model background earthquakes that include a low probability of earthquakes by using the Gutenberg-Richter formula or other statistical techniques to compensate the long-term evaluation;

(2) Preparation of strong ground motion maps considering low-probability earthquakes.
In addition to traditional information dissemination to emphasize the urgency of the earthquake occurrence by showing the probability, by going back to the original purpose of the evaluation of probabilistic seismic hazard, we should prepare the maps that show the strong-motion level for earthquake preparedness. For example, based on the averaged long-term seismic 
hazard assessment, evaluating strong-motion level for about 10,000-100,000 years return period, we should prepare the maps that show the distribution of strong-motion level, which represent effect of major earthquakes on active faults and subduction zone earthquakes with low-probability. Regarding the seismic hazard assessment for low probability, at present, it is insufficient to evaluate the uncertainty for low probability M8 class earthquakes and it is necessary to improve techniques for them;

(3) Development of methodology for selecting appropriate scenario earthquakes from probabilistic seismicity model.

In the seismic activity model considering low-probability earthquakes, not only earthquakes with specified faults, but also earthquakes without specified faults are included. From the seismic activity model, it is necessary to establish a methodology that can be selected as appropriate scenario earthquakes for purposes of earthquake preparedness;

(4) Development of methodology for prediction of strong ground motions for mega earthquakes.

In order to perform seismic hazard assessment considered the low-probability events until about 10,000 years return period, it is necessary to predict strong ground motions for large earthquakes that have not been recorded by the modern seismic observation network. For the "Method for prediction of strong ground motion for earthquakes with specified faults (recipe)", which is currently being used for strong motion prediction, the subduction zone earthquakes up to about M8 and earthquakes on active fault up to about $80 \mathrm{~km}$ in length are only verified its scope. The sophistication of techniques that can be applied to the prediction of strong ground motions for super large earthquakes are required.

\section{Acknowledgments}

This study was conducted as a part of the research on advanced seismic hazard assessment for the National seismic hazard maps for Japan.

\section{References}

[1] Headquarters for Earthquake Research Promotion of Japan, National seismic hazard maps for Japan, 2009.

[2] H. Fujiwara, T. Kunugi, S. Adachi, S. Aoi and N. Morikawa, New K-NET: Development of real-time system for strong-motion observation, Journal of JAEE 7 (2) (2007) 2-16.

[3] S. Aoi, T. Kunugi, H. Nakamura and H. Fujiwara, Deployment of new strong motion seismographs of K-NET and KiK-net, Earthquake Data in Engineering Seismology, Geotechnical, Geological, and Earthquake Engineering, Springer 14 (2011) 167-186.

[4] W. Suzuki, S. Aoi, H. Sekiguchi and T. Kunugi, Rupture process of the 2011 Tohoku-Oki mega-thrust earthquake (M9.0) inverted from strong-motion data, Geophys. Res. Lett. 38 (2011) 6.

[5] H. Fujiwara, S. Kawai, S. Aoi, N. Morikawa, S. Senna and N. Kudo et al., Technical Reports on National Seismic Hazard Maps for Japan, Vol. 336, Technical note of the National Research Institute for Earth Science and Disaster Prevention, 2009.

[6] K. Wakamatsu and M. Matsuoka, Development of nationwide GIS-based 7.5-arc-second Japan engineering geomorphologic classification map, in: Proceedings of Annual Meeting of JAEE, 2008, pp. 222-223.

[7] National Research Institute for Earth Science and Disaster Prevention, Japan Seismic Hazard Information Station (J-SHIS), available online at: http://www.j-shis.bosai.go.jp.

[8] Headquarters for Earthquake Research Promotion of Japan, Long-term evaluation of seismic activity for the region from the off Sanriku to the off Boso, 2009. 